\title{
Dialysis Disequilibrium Syndrome: Brain death following hemodialysis for metabolic acidosis and acute renal failure - A case report
}

\author{
Sean M Bagshaw ${ }^{* 1,2}$, Adam D Peets ${ }^{1}$, Morad Hameed ${ }^{1,3}$, Paul JE Boiteau ${ }^{1}$, \\ Kevin B Laupland ${ }^{1,4,5}$ and Christopher J Doig 1,2
}

\begin{abstract}
Address: ${ }^{1}$ Department of Critical Care Medicine, Calgary Health Region and University of Calgary, Calgary, Alberta, Canada, ${ }^{2}$ Department of Community Health Sciences, Calgary Health Region and University of Calgary, Calgary, Alberta, Canada, ${ }^{3}$ Department of Surgery, Calgary Health Region and University of Calgary, Calgary, Alberta, Canada, ${ }^{4}$ Department of Medicine, Calgary Health Region and University of Calgary, Calgary, Alberta, Canada and ${ }^{5}$ Department of Diagnostic and Laboratory Medicine, Calgary Health Region and University of Calgary, Calgary, Alberta, Canada
\end{abstract}

Email: Sean M Bagshaw* - smbagsha@ucalgary.ca; Adam D Peets - adpeets@ucalgary.ca;

Morad Hameed - morad.hameed@calgaryhealthregion.ca; Paul JE Boiteau - paul.boiteau@calgaryhealthregion.ca;

Kevin B Laupland - kevin.laupland@calgaryhealthregion.ca; Christopher J Doig - cdoig@ucalgary.ca

* Corresponding author

Published: 19 August 2004

BMC Nephrology 2004, 5:9 doi:10.1 186/147/-2369-5-9
Received: 21 May 2004

Accepted: 19 August 2004

This article is available from: http://www.biomedcentral.com/I47/-2369/5/9

(c) 2004 Bagshaw et al; licensee BioMed Central Ltd.

This is an open-access article distributed under the terms of the Creative Commons Attribution License (http://creativecommons.org/licenses/by/2.0), which permits unrestricted use, distribution, and reproduction in any medium, provided the original work is properly cited.

\begin{abstract}
Background: Dialysis disequilibrium syndrome (DDS) is the clinical phenomenon of acute neurologic symptoms attributed to cerebral edema that occurs during or following intermittent hemodialysis (HD). We describe a case of DDS-induced cerebral edema that resulted in irreversible brain injury and death following acute HD and review the relevant literature of the association of DDS and HD.
\end{abstract}

Case Presentation: A 22-year-old male with obstructive uropathy presented to hospital with severe sepsis syndrome secondary to pneumonia. Laboratory investigations included a $\mathrm{pH}$ of 6.95 , $\mathrm{PaCO} 210 \mathrm{mmHg}, \mathrm{HCO} 32 \mathrm{mmol} / \mathrm{L}$, serum sodium $132 \mathrm{mmol} / \mathrm{L}$, serum osmolality $330 \mathrm{mosmol} / \mathrm{kg}$, and urea $130 \mathrm{mg} / \mathrm{dL}(46.7 \mathrm{mmol} / \mathrm{L})$. Diagnostic imaging demonstrated multifocal pneumonia, bilateral hydronephrosis and bladder wall thickening. During HD the patient became progressively obtunded. Repeat laboratory investigations showed $\mathrm{pH} \mathrm{7.36,} \mathrm{HCO3} 19 \mathrm{mmol} / \mathrm{L}$, potassium 1.8 $\mathrm{mmol} / \mathrm{L}$, and urea $38.4 \mathrm{mg} / \mathrm{dL}(13.7 \mathrm{mmol} / \mathrm{L}$ ) (urea-reduction-ratio $71 \%$ ). Following $\mathrm{HD}$, spontaneous movements were absent with no pupillary or brainstem reflexes. Head CT-scan showed diffuse cerebral edema with effacement of basal cisterns and generalized loss of gray-white differentiation. Brain death was declared.

Conclusions: Death is a rare consequence of DDS in adults following HD. Several features may have predisposed this patient to DDS including: central nervous system adaptations from chronic kidney disease with efficient serum urea removal and correction of serum hyperosmolality; severe cerebral intracellular acidosis; relative hypercapnea; and post-HD hemodynamic instability with compounded cerebral ischemia. 


\section{Background}

Acute renal failure requiring hemodialysis (HD) is a common clinical problem in critically ill patients that is independently associated with increased mortality[1]. Dialysis disequilibrium syndrome (DDS) is the clinical phenomenon of acute central nervous system dysfunction attributed to cerebral edema that occurs during or following HD. The precise epidemiology of DDS is poorly defined[2]. Review of MEDLINE (January 1966 - March 2004) suggested that DDS in critically ill patients has rarely been reported[3,4]. We report a case of DDSinduced cerebral edema that resulted in irreversible brain injury and death following acute HD. Further, we review the relevant literature of the association of DDS and HD.

\section{Case presentation}

A 22-year-old homosexual male presented to hospital with progressive dyspnea, productive cough, generalized malaise and fever. He had a known history of intravenous cocaine abuse and recent serology in prior 3 months was negative for human immunodeficiency virus (HIV). Results of a physical examination showed signs of tachypnea, tachycardia, accessory muscle use and left lung base crackles. Tympanic temperature was $34.7^{\circ} \mathrm{C}$. The remainder of the examination was unremarkable except for urethral meatus stenosis.

Initial laboratory investigations are presented in Table 1. Arterial blood gases showed $\mathrm{pH}$ of $6.95, \mathrm{PaCO}_{2} 10$ $\mathrm{mmHg}, \mathrm{PaO}_{2} 109 \mathrm{mmHg}, \mathrm{HCO}_{3} 2 \mathrm{mmol} / \mathrm{L}$, and lactate $0.6 \mathrm{mmol} / \mathrm{L}$ consistent with high anion gap metabolic acidosis with respiratory compensation. Serum creatinine and blood urea nitrogen were $587 \mu \mathrm{mol} / \mathrm{L}$ and 46.7 $\mathrm{mmol} / \mathrm{L}$, respectively. Toxicology and drug screen was negative. The metabolic acidosis was partially accounted for by acute renal failure with retained unmeasured anions and ketonemia. Urinalysis showed pyuria. Electrocardiogram (ECG) showed normal sinus rhythm.

Chest radiograph revealed right middle lobe and lingular patchy opacification. An abdomino-pelvic CT scan demonstrated moderate to severe bilateral hydronephrosis, bladder wall thickening with multiple diverticuli, and retroperitoneal streaking consistent with acute infection. A provisional diagnosis of severe sepsis was made with multiple potential foci of infection. The patient was given empiric ceftriaxone, metronidazole and vancomycin. Sputum specimen cultured heavy methicillin-sensitive Staphylococcus aureus, blood cultures were positive for $S$. aureus, Escherichia coli, and Group B Streptococcus. Urine cultured greater than $10^{8} \mathrm{CFU} / \mathrm{L}$ of multiple gram positive and negative organisms.

The patient was admitted to the intensive care unit (ICU). The metabolic acidosis persisted (pH 7.00) a despite 100
$\mathrm{mEq}$ of $8.4 \%$ sodium bicarbonate bolus and infusion of three liters of normal bicarbonate solution $(150 \mathrm{mEq}$ of $8.4 \%$ sodium bicarbonate in $1000 \mathrm{~mL}$ D5W). The patient had a suprapubic bladder catheter inserted by angiography. However, due to concern the patient remained oliguric following $4 \mathrm{~L}$ crystalloid resuscitation, hemodialysis was organized. Hemodialysis parameters included: F160 membrane (surface area $1.5 \mathrm{~m}^{2}$ and KUf $50 \mathrm{~mL} / \mathrm{hr} /$ $\mathrm{mmHg}$ ), dialysate sodium $136 \mathrm{mmol} / \mathrm{L}$, potassium 3 $\mathrm{mmol} / \mathrm{L}$, calcium $1.25 \mathrm{mmol} / \mathrm{L}$, bicarbonate $40 \mathrm{mmol} / \mathrm{L}$, and $\mathrm{Q}_{\mathrm{D}} 500 \mathrm{~mL} / \mathrm{min}, \mathrm{Q}_{\mathrm{B}} 250-300 \mathrm{~mL} / \mathrm{min}$ via a $25 \mathrm{~cm}$ left femoral double-lumen Uldall catheter. The patient had $71.5 \mathrm{~L}$ of blood processed over four hours with no fluid removal. Although the patient was alert and appropriate (Glasgow Coma Scale 15) with tachycardia and stable normal range blood pressure before the initiation of dialysis, he was demonstrating an increased work of breathing and oxygen requirements suggestive of worsening sepsis syndrome. Approximately $2.5 \mathrm{hrs}$ after start of dialysis the patient became rapidly unresponsive prompting intubation for airway protection. At completion of HD and over the subsequent 4 hours the patient's neurologic status deteriorated with evidence of loss of all brainstem reflexes. Head CT-scan is shown in Figure 1.

Repeat laboratory investigations immediately following hemodialysis revealed a $\mathrm{pH} 7.36, \mathrm{HCO} 319 \mathrm{mmol} / \mathrm{L}$, sodium $132 \mathrm{mmol} / \mathrm{L}$, potassium $1.8 \mathrm{mmol} / \mathrm{L}$, and urea $13.7 \mathrm{mmol} / \mathrm{L}$ (urea-reduction-ratio was 71\%) (Table 1).

The patient rapidly progressed to refractory shock and multi-organ dysfunction Diagnosis of brain death was declared independently by an intensivist and a neurologist. At autopsy, the brain showed evidence of diffuse cerebral edema. Cardiac assessment showed left ventricular enlargement consistent with systemic hypertension likely as a result of chronic kidney disease. Both lungs showed patchy acute bronchopneumonia with edema and congestion. Both kidneys appeared grossly pyonephrotic with dilated, thickened ureters and suggested the presence of acute on chronic pyelonephritis. The meatal aperture was scarred and stenosed.

\section{Discussion}

The immediate indication for renal replacement therapy was correction of refractory metabolic acidosis in the setting of oliguria; however, following initiation of HD this patient developed irreversible symptoms consistent with DDS.

DDS occurs most commonly following initiation of chronic HD for patients with end-stage renal disease[2]. Patients with pre-existing neurologic disease, such as head trauma, stroke or malignant hypertension, may be at greater risk for developing DDS[5,6]. The precise epidemi- 
Table I: Laboratory values at prior to and following initiation of hemodialysis in the intensive care unit.

\begin{tabular}{lccc}
\hline Laboratory test & Pre-dialysis Value & Post-dialysis Values & Reference range \\
\hline Hemoglobin & 96 & 78 & $137-180 \mathrm{~g} / \mathrm{L}$ \\
White cell count & 25.8 & 16.1 & $4.0-11.0 \times 109 / \mathrm{L}$ \\
Band count & 3.1 & - & $0.0-1.3 \times 109 / \mathrm{L}$ \\
Platelets & 603 & 486 & $150-400 \times 109 / \mathrm{L}$ \\
Sodium & 132 & 132 & $133-145 \mathrm{mmol} / \mathrm{L}$ \\
Potassium & 3.1 & 1.8 & $3.5-5.0 \mathrm{mmol} / \mathrm{L}$ \\
Chloride & 107 & 93 & $98-111 \mathrm{mmol} / \mathrm{L}$ \\
Bicarbonate & 2 & 19 & $21-31 \mathrm{mmol} / \mathrm{L}$ \\
Glucose & 6.3 & 9.0 & $3.6-11.1 \mathrm{mmol} / \mathrm{L}$ \\
Magnesium & 0.88 & 0.57 & $0.65-1.15 \mathrm{mmol} / \mathrm{L}$ \\
Osmolality & 330 & - & $280-300 \mathrm{mosmol} / \mathrm{kg}$ \\
Urea & 46.7 & 13.7 & $3.0-7.6 \mathrm{mmol} / \mathrm{L}$ \\
Creatinine & 537 & - & $61-111 \mu \mathrm{mol} / \mathrm{L}$ \\
Lactate & 0.6 & 1.2 & $<2.0 \mathrm{mmol} / \mathrm{L}$ \\
Serum ketones & $2+$ & - & $\mathrm{ndetected}$ \\
Anion gap & 23 & 20 & $12-14$ \\
Osmolar gap & 14.5 & - & $0-10$ \\
\hline
\end{tabular}

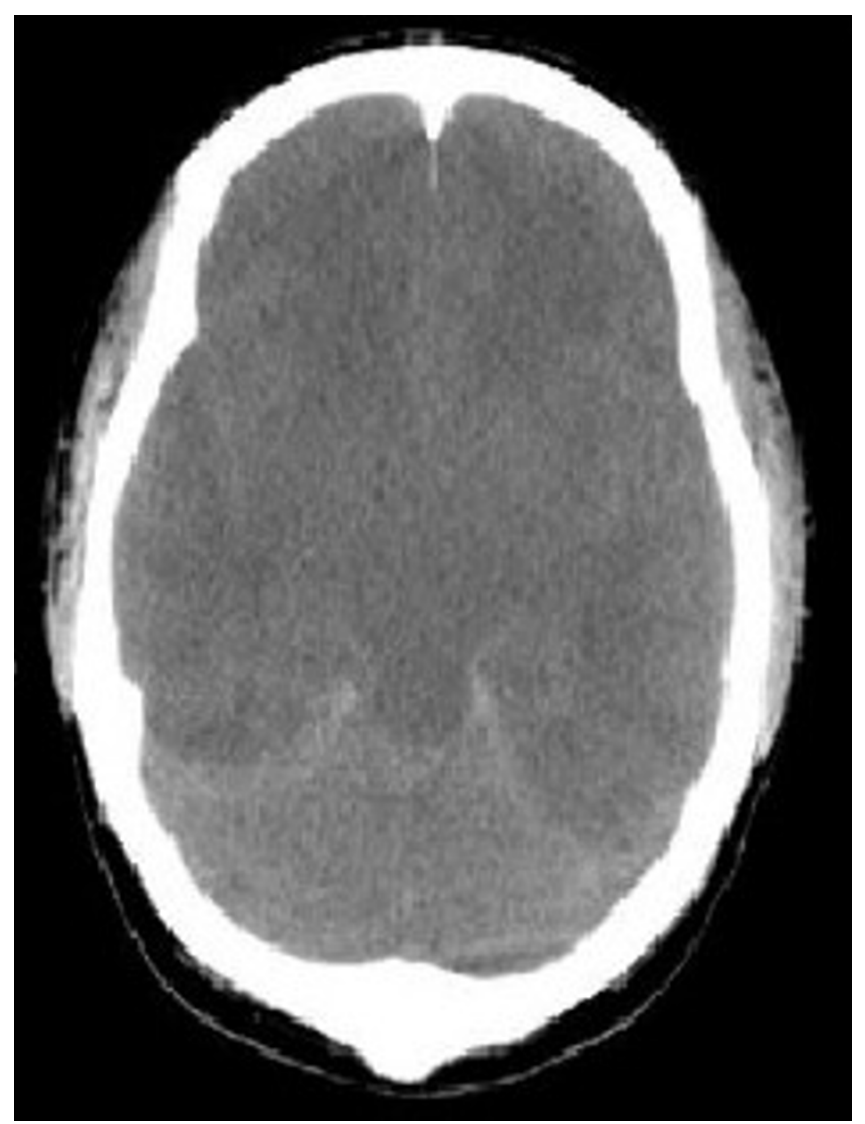

Figure I

Computerized Tomography (CT) head showing diffuse cerebral edema with effacement of basal cisterns and generalized loss of gray-white differentiation ology of DDS is poorly defined and may be underreported due to the wide spectrum of clinical manifestations. Mild symptoms such as headache, nausea, blurred vision, muscle cramps, disorientation, anorexia, restlessness, hypertension and dizziness are common during or following HD and may be attributed to DDS[2]. More severe symptoms consistent with central nervous system dysfunction such as seizures, central pontine myelinolysis, coma and death are rare[7]. The temporal profile for DDS is not well described. DDS has been credited for acute electroencephalographic (EEG) abnormalities and structural changes on diagnostic imaging following rapid hemodialysis [8-10]. Likewise, brain MRI studies immediately following hemodialysis in chronic dialysis patients have shown quantitative increases in brain volume consistent with cerebral edema[11].

The pathogenesis remains debated and incompletely understood; however, two central hypotheses have emerged. First, acute urea removal occurs more slowly across the blood-brain barrier than from plasma, generating a 'reverse osmotic gradient' promoting water movement into the brain and cerebral edema[12]. Absolute increases in brain water content have been demonstrated in a rat model of uremia undergoing rapid hemodialysis that was accounted for by an increase in the ratio of brain to plasma urea $[13,14]$. Down-regulation of central nervous system urea transporters have been proposed as a mechanism contributing to the delay in urea clearance from the brain[15].

The second hypothesis states that the increased osmolality of the extracellular fluid in uremia stimulates an adaptive 
accumulation of intracellular organic osmolytes to limit cerebral cell dehydration[16]. During hemodialysis, retention of these organic osmolytes contributes to a paradoxical reduction in intracellular $\mathrm{pH}$ resulting in increased brain osmolality and cerebral edema $[17,18]$.

The patient in this case unfortunately may have been susceptible to both proposed pathophysiologic mechanisms. The likely and under-appreciated presence of pre-existing kidney disease (chronic obstructive nephropathy and pyelonephritis) with an increased serum osmolality would have resulted in adaptive changes in the central nervous system. Ensuing hemodialysis correction of the plasma metabolic acidosis may have eclipsed a more severe cerebral intracellular acidosis. Further, urea clearance by hemodialysis was efficient at approximately $70 \%$ and probably generated a sufficient plasma-to-brain urea gradient for development of cerebral edema, intracranial hypertension and DDS. A less efficient initial course of hemodialysis would have diminished the osmolar gradient of urea across the central nervous system reducing the likelihood of symptoms of DDS.

Other variables may have contributed. The patient was compensating for the severe metabolic acidosis by hyperventilation $\left(\mathrm{PaCO}_{2} 10 \mathrm{mmHg}\right)$; however, initial postintubation $\mathrm{PaCO}_{2}$ was $42 \mathrm{mmHg}$. Rapid elevations in $\mathrm{PaCO}_{2}$ can alter cerebral autoregulation resulting in exacerbated intracranial hypertension[19]. Concomitant sepsis syndrome with poly-microbial bacteremia resulting in widespread immune activation may alter blood-brainbarrier permeability and contribute to cerebral edema[20,21]. These factors likely contributed to an increased risk for DDS-induced cerebral edema.

The symptoms of DDS have been ameliorated by several interventions targeted to reduce the hemodialysisinduced plasma-to-brain osmotic gradient promoting cerebral edema[22]. A similar case of severe DDS requiring intubation was prevented from recurring during subsequent hemodialysis by use of modified dialysate containing $10.1 \mathrm{mmol} / \mathrm{L}$ of urea[23]. Likewise, the administration of intravenous mannitol and hyperventilation reversed a case of severe DDS-induced central nervous system dysfunction in a patient undergoing initial hemodialysis for acute renal failure[3]. Conversely, sodium profiling, high sodium or hyperglycemic dialysate have been attempted with variable results[24,25].

Prevention of DDS is traditionally the mainstay of therapy, particularly during initiation of hemodialysis in new patients. Despite the absence of evidence-based guidelines, the conventional aim is for a gradual clearance of urea. This can be accomplished with intermittent hemodialysis by use of a smaller, less efficient dialyzer and by reducing the duration of initial dialysis to approximately 2 hours with targeted lower blood flow rates of 150-200 $\mathrm{mL} / \mathrm{min}$, use of sustained low-efficiency dialysis (SLED), or initiation of continuous renal replacement therapy (CRRT) with more gradual and stable clearance of urea[2,26-28]. As a result, DDS has not been reported with the use of SLED or CRRT in critically ill patients. By providing a shorter, less efficient trial of initial hemodialysis, the severe DDS and brain death in this case may have been altogether prevented.

In summary, the precise epidemiology and pathophysiology of DDS remain unclear. Although DDS usually presents in end-stage renal disease patients undergoing initial therapy, critically ill patients may represent a unique population where co-existing illnesses such as sepsis, brain injury or other central nervous system disease, multiorgan dysfunction, and need for sedation can present obstacles for prompt diagnosis of DDS. Furthermore, for similar reasons, critically ill patients may have increased susceptibility to DDS conditions.

\section{Competing interests}

None declared.

\section{Authors' contributions}

SMB wrote and revised the manuscript. ADP, MH, PJEB, KBL and CJD provided critique of successive drafts of the manuscript. All authors read and approved the final manuscript.

\section{Acknowledgements}

The authors would like to thank Dr. Bruce Culleton, (Division of Nephrology, Department of Medicine, University of Calgary) for critical review of this manuscript.

\section{References}

I. Liano F, Pascual J: Epidemiology of acute renal failure: a prospective, multicenter, community-based study. Kidney Internat 1996, 50:81I-8181.

2. Arieff $A$ : Dialysis disequilibrium syndrome: Current concepts on pathogenesis and prevention. Kidney Internat 1994, 45:629-635.

3. DiFresco V, Landman M, Jaber B, White A: Dialysis disequilibrium syndrome: an unusual cause of respiratory failure in the medical intensive care unit. Intensive Care Medicine 2000, 26:628-630.

4. Harris C, Townsend J: Dialysis disequilibrium syndrome: Clinicopathologic conference. West J Med 1989, 1 5 1:52-55.

5. Peterson $\mathrm{H}$ : Acute encephalopathy occurring during hemodialysis. Arch Intern Med 1964, II 3:877-880.

6. Yoshida S, Tajika T, Yamasaki N, Tanikawa T, Kitamura K, Kudo K, Lyden $\mathrm{P}$ : Dialysis dysequilibrium syndrome in neurosurgical patients. Neurosurgery 1987, 20:716-721.

7. Aydin O, Uner C, Senbil N, Bek K, Erdogan O, Gurer Y: Central pontine and extrapontine myelinolysis owing to disequilibrium syndrome. J Child Neurol 2003:292-296.

8. Meyrier A, Blanc E, Reignier A, Richet G: Unusual aspects of the dialysis disequilibrium syndrome. Clin Nephrol 1976, 6:3 I I-3 I4.

9. LaGreca G, Biasioli S, Chiaramonte S, Dettori P, Fabris A, Feriani M, Pinna V, Pisani ECR: Studies on brain density in hemodialysis and peritoneal dialysis. Nephron 1982, 31:146-150. 
10. Sheth $K$, Messe $S$, Wolf $R$, Kasner $S$ : Dialysis disequilibrium: another reversible posterior leukoencephalopathy syndrome? Clin Neurol Neurosurg 2003, 105:249-252.

II. Walters R, Fox N, Crum W, Taube D, Thomas D: Haemodialysis and cerebral oedema. Nephron 200I, 87:143-I47.

12. Silver S, Sterns R, Halperin M: Brain swelling after dialysis: Old urea or new osmoles? Am J Kidney Dis 1996, 28: I-I3.

13. Silver S, DeSimone J Jr, Smith D, Sterns R: Dialysis disequilibrium syndrome (DDS) in the rat: Role of the "reverse urea effect". Kidney Internat 1992, 42:161-166.

14. Silver $\mathrm{S}$ : Cerebral edema after rapid dialysis is not caused by an increase in brain organic osmolytes. J Am Soc Nephrol 1995, 6:1600-1606.

15. Hu M, Bankir L, Michelet S, Rousselet G, Trinh-Trang-Tan M: Massive reduction of urea transporters in remnant kidney and brain in uremic rats. Kidney Internat 2000, 58:1202-1210.

16. Arieff A, Massry S, Barrientos A, Kleeman C: Brain water and electrolyte metabolism in uremia: Effects of slow and rapid hemodialysis. Kidney Internat 1973, 4:177-I87.

17. Arieff A, Guisade R, Massry S, Lazarowitz V: Central nervous system $\mathrm{pH}$ in uremia and the effects of hemodialysis. J Clin Invest 1976, 58:306-31।.

18. Trachtman H, Futterweit S, Tonidandel W, Gullans S: The role of organic osmolytes in the cerebral cell volume regulatory response to acute and chronic renal failure. J Am Soc Nephrol 1993, 3:1913-1919.

19. Oertel M, Kelly D, Lee J, McArthur D, Glenn T, Vespa P, Boscardin W, Hovda D, Martin NA: Efficacy of hyperventilation, blood pressure elevation, and metabolic suppression therapy in controlling intracranial pressure after head injury. J Neurosurg 2002, 97:1045-1053.

20. Schilling L, Wahl M: Brain edema: pathogenesis and therapy. Kidney Intern 1997, 59:S69-S75.

21. Davies D: Blood-brain barrier breakdown in septic encephalopathy and brain tumors. J Anat 2002, 200:639-646.

22. Port F, Johnson W, Klass D: Prevention of dialysis disequilibrium syndrome by use of high sodium concentration in the dialysate. Kidney Internat 1973, 3:327-333.

23. Doorenbos C, Bosma R, Lamberts P: Use of urea containing dialysate to avoid disequilibrium syndrome, enabling intensive dialysis treatment in a diabetic patient with renal failure and severe metformin induced lactic acidosis. Nephrol Dial Transplant 200I, 16:1303-1304.

24. Gutman R, Hickman R, Chatrian G, Scribner B: Failure of high dialysis-fluid glucose to prevent the disequilibrium syndrome. Lancet 1967, I I:295-298.

25. Stiller S, Bonnie-Schorn E, Grassman A, Uhlenbusch-Korwer I, Mann $\mathrm{H}$ : A critical review of sodium profiling for hemodialysis. Semin Dial 200I, 14:337-347.

26. Kishimoto T, Yamagami S, Tanaka H, Ohyama T, Yamamoto T, Yamakawa M, Nishino M, Yoshimoto S, Maekawa M: Superiority of hemofiltration to hemodialysis for treatment of chronic renal failure: comparative studies between hemofiltration and hemodialysis on dialysis disequilibrium syndrome. Artif Organs 1980, 4:86-93.

27. Marshall M, Golper T, Shaver M, Alam M, Chatoth D: Sustain lowefficiency dialysis for critically ill patients requiring renal replacement therapy. Kidney Intern 200I, 60:777-785.

28. Marshall M, Golper T, Shaver M, Alam M, Chatoth D: Urea kinetics during sustained low-efficiency dialysis in critically ill patients requiring renal replacement therapy. Am J Kidney Dis 2002, 39:556-570

\section{Pre-publication history}

The pre-publication history for this paper can be accessed here:

http://www.biomedcentral.com/1471-2369/5/9/prepub
Publish with Biomed Central and every scientist can read your work free of charge

"BioMed Central will be the most significant development for disseminating the results of biomedical research in our lifetime. "

Sir Paul Nurse, Cancer Research UK

Your research papers will be:

- available free of charge to the entire biomedical community

- peer reviewed and published immediately upon acceptance

- cited in PubMed and archived on PubMed Central

- yours - you keep the copyright
BioMedcentral 